\title{
Analysis of Mode of Cultural-industry Talents Training at Independent Colleges in Hebei Province
}

\author{
Hong ZHANG \& Jia LIU \& Libo SHI \& Cheng CHENG \\ Polytechnic College, Hebei University of Science and Technology, Shijiazhuang, Hebei, China
}

\begin{abstract}
With the advent of the era of global information, the culture is playing an increasingly important role in society. The cultural industry is becoming the "sunrise industry" along with the revolution of new science and technology and thus gets more and more attention. However, the development of the cultural industry faces the bottleneck of lacking the professionals of cultural industry. Therefore, for the independent colleges where a large number of talents are cultivated and exported to the society, they should take the obligatory responsibility for cultivating and exporting applicationoriented and innovative talents of cultural industry in order to provide a strong talent and intelligence support and new impetus for the prosperity of the cultural development as well as in Hebei Province. This article analyzes the current situation of cultural industry talents training in Hebei province, focuses on an integrated cultural industry talents training model at independent colleges in Hebei, which is feasible to independent colleges and has great impact upon the strategic cultural development in Hebei.
\end{abstract}

KEYWORD: Hebei province; cultural- industry talents; personnel training mode

\section{INTRODUCTION}

In recent years, China's cultural industry has been developing increasingly in large scale, contributing more and more to the national gross product and the economy. According to the preliminary estimates of the National Bureau of Statistics, the value of cultural industry in 2009 was 840 billion yuan, increasing by $10 \%$ than that in 2008, which exceeded the GDP growth rate. "At the Eighth Hebei Party Congress in November 2011, provincial Party secretary Comrade Zhang Qingli pointed out that we should promote the development and prosperity of Hebei culture, achieve the development of a strong cultural province. The construction of cultural province lies in cultivating more talents. Colleges and universities in the new era should be the base for cultural-industry talents training, to meet the needs of society. Scientific training mode becomes the best incubator of cultural industry development in our province. Therefore, in the competitive market, in the flourishing cultural industry, with the shortage of cultural talents, it is important to find out the obstacle and solutions to the development of culture.

\section{ANALYSIS OF THE CURRENT SITUATION IN HEBEI CULTURE INDUSTRY TALENTS IN COLLEGES AND UNIVERSITIES}

With the rapid development of China and culture industry in the world, cultural industry education and related disciplines in Hebei province have entered a new stage of rapid development. Three universities in Hebei provide the major of cultural industry, approved by the national ministry of education. They are: Hebei University of Economics and Business, Shijiazhuang University and Hebei Institute of Media. By cooperation with some businesses, some other universities establish some cultural research organizations and bases, even though there is no explicit culture industry major in the schools. For example, Hebei University, Hebei Normal University and some other provincial universities have jointly set up some cultural industry bases or research institutions, such as Institute of Huaxia Culture Industry at Hebei University, which is joint established with National Development and Reform Commission established. Hebei Normal University and Shijiazhuang Guoda Group jointly created Creative Culture Park. These institutions relying on university resources, provide 
catalyst and intellectual support for the development and prosperity of culture industry in Hebei province. But judging from the current situation, the major is only offered in some key universities in Hebei, such as Hebei University, Hebei Normal University, Hebei University of Economics and Business. The major is rarely given in independent colleges. If there is any, the focus is not on cultural industry. Therefore, the investment in cultivating culturalindustry talents cannot meet the needs; the cultural industry development of our province at present, the number of practitioners in the cultural industry and related fields of our province is far lower than that in Beijing, Shanghai, Shandong and other provinces and cities; the size of the enterprise and number of industry leader are below average, which seriously constrains the development of cultural industry in our province, even though independent college graduates amount to $40 \%$ of the total number in Hebei. Independent colleges train and provide a large number of innovative personnel for Hebei culture industry and mass transportation, powering and offering strong intellectual support for the development and prosperity of Hebei culture.

\subsection{Weak consciousness of culture industry talents training}

At present, although the cultural strategy of strong Hebei is proposed, compared with other provinces, especially the independent institutes in Hebei, cultural industry professionals are rare. The only specialty established in Hebei is from Bebei University of Economy and Trade, Shijiazhuang University and others. Even in these schools, the training mode for culture industry talents is very traditional, because of the lack of technical guidance and operational experience. There is more focus on theory than on practice, thus making the culture industry talents often lack of practical ability, failing to meet the demands of society. On the selection of teaching materials, no unified and common textbooks are compiled. Each school adopts its own teaching material according to their environments, which greatly affects the unity and practical application of the culture industry talents.

\subsection{Cultural-industry specialty setup is not up-to- date}

In view of the economic contribution of cultural industry and scarcity of cultural talents, the ministry of education has approved more comprehensive universities to set up cultural-industry specialty since the 16th National Congress of the CPC, in order to promote culture industry talents training. This makes talent cultivation flourishing. More and more universities began setting up cultural-industry specialty. But Hebei universities are far left behind, due to inadequate preparations, unclear professional training objectives and unawareness of the social demand. For example, the major of culture or cultural-industry management is very ambiguous so some basic courses in the curriculum are so easy that students in these schools have less advantage. They have mastered some common but less professional and specialized knowledge. Therefore, it is very difficult for them to perform the actual work upon graduation.

\subsection{Cultural-industry teachers are in short.}

Talents cultivation cannot do without a solid team of teachers as the guarantee, as currently envisaged, however, lack of teachers is indeed a real problem. This is especially true for independent colleges. The reasons are as follows. On the one hand, talents cultivation is a new type of professional discipline, and it's not offered in some independent colleges. On the other hand, most of the teachers in the independent colleges belong to the mother universities, more traditional ones. Many teachers place their priority on their own majors, but don't want to turn to talents cultivation, even though some teachers participate in some cultural-industry talents training programs. Generally speaking, colleges and universities are lack of teachers who have culturalindustry qualifications or diplomas.

\subsection{The training programs are not scientific}

Culture industry talents are generally referred to as three types: the first one is engaged in the theory research; the second is about cultural-industry creativity; the third is about cultural-industry management. But some programs in colleges and universities in our province are not in accordance with the practical national curriculum. Some graduates from the universities are left behind in both theory and practice in this field, which remains a disadvantage for the students. Some colleges offer the programs by making use of their existing majors, which have less connection to culturalindustry.

\section{PROPOSALS FOR ESTABLISHING TEACHING MODES IN THE INDEPENDENT COLLEGES}

\subsection{Clear objectives to balance between supply and demand of cultural-industry talents}

Under the condition of market economy, the cultural-industry structure presents the diversification, the characteristics of richness, which directly affects independent colleges in terms of diversity of cultural-industry talents and diverse demand. That is the focus of cultivation model of 
culture industry training in independent colleges. Since most teachers in independent colleges are from the mother universities, the training schemes, teaching methods and techniques are more theoryoriented. There is some deviation from practical cultural-industry talents, therefore, independent colleges must first set up clear and specific objectives, make feasible cultivation measures, make the student's own development combine with the social needs. Second, education in independent colleges should be based on their own characteristics, lay emphasis on Beijing-TianjinHebei regional economy development, and put market demand as top priority, striving to cultivate the students' practical ability and innovation ability, actively exploring joint training. Independent colleges should be in accordance with needs of social development, be clear about their positioning, goals, service for the development of cultural industry.

\subsection{Improving the abilities of teaching staff, enhancing the capacity of cultural industry talents training}

The enlightenment of cultural industry of independent colleges in our province is behind time, the foundation is not so solid, and the number of teachers is insufficient. In order to enhance the capacity of cultural industry talents in independent colleges, independent colleges must strengthen the cultural industry's construction in our province and refine cultural industry's professional classification. In the professional positioning, firstly we should take advantage of their academic excellence and specialty characteristics. Secondly, we take into consideration the actual situation of cultural industry in Beijing-Tianjin-Hebei region. Thus we should optimize the resources, give full play to the advantages of independent colleges, and keep the characteristics of the colleges. The proposal is that we should continue offering information technology majors in technology colleges, and management in liberal arts schools. At the same time, the independent colleges in our province should improve abilities of teaching staff. On one hand, we should offer training and guidance to the teachers whose work is related to the existing cultural industry. We should integrate teachers' professional characteristics, and cultivate talents of practical and compound type. What's more, we should create opportunities to let the professional teachers go out of their own schools and go to other universities or provinces for further education. Or we can send them directly to the cultural industry companies to do some practical work and broaden the horizons and practical abilities. We should take into account the fact that independent colleges are cooperativelyrun schools that emerged in recent ten years, the teachers are less competitive than those in traditional universities, and there exist difficulties in introducing high-quality teachers. In view of that, we can strengthen the cooperation between independent colleges, encourage "a teacher with multi-tasks", and share all teaching resources. We can also invite teachers with practical experience as visiting professors and so on. Finally we should achieve improvement of overall abilities of teachers in independent colleges in our province.

\subsection{Combining learning with research, strengthening cooperation with enterprises and institutions, building teaching practice bases}

The goal of Independent colleges is to cultivate talents for the service of economic and social development in Beijing-Tianjin-Hebei region, therefore, independent colleges should take full consideration into social needs, strengthen their characteristics, choose and employ persons to cultivate practical talents for cultural enterprises and institutions, establish practice teaching bases, visit cultural enterprises, participate in the development of the talent training schemes, give full play to cultural enterprises and institutions and the enthusiasm of the cooperation training talents, introduce enterprise culture conceptions, values, make the cultural-industry management be in accordance with the needs of society, enhance teaching pertinence, effectiveness, and constantly adjust to social development. In this way, culturalindustry talents will be more adaptable to the society, more competitive in Hebei province.

\section{REFERENCES}

[1] Lei Zhao. The changing experiences and challenges of internal migrants in China: Female migrant workers in Beijing hotel industry. University of Massachusetts Lowell, 2009.

[2] Karen Goodlad. The American wine industry: Key issues from Prohibition to the $21 \mathrm{st}$ century and beyond. State University of New York Empire State College, 2009.

[3] Jennifer (Perky) Beisel. The American upper class and the American horse industry from 1865 to 1929. Middle Tennessee State University, 2005.

[4] Etienne Hirsch, Yves Joanette. Global action against dementia legacy event: Harnessing the power of discoveries - capitalizing on the synergies between academia and industry. Alzheimer's \& Dementia: The Journal of the Alzheimer's Association, 2014, 10(4). 